R. Buccheri et al. (eds.); Endophysics, Time, Quantum and the Subjective; 507-530

(C) 2005 World Scientific Publishing Co. All rights reserved.

\title{
OUT-OF-BODY, OUT-OF-TIME. ABNORMAL UNITY OF BODY AND SELF IN SPACE AND TIME
}

\author{
SHAHAR ARZY, ${ }^{1,2,3}$ THEODOR LANDIS ${ }^{3}$ and OLAF BLANKE ${ }^{1,3 a}$ \\ ${ }^{1}$ Lab. of Cognitive Neuroscience, École Polytechnique Fédérale de Lausanne (EPFL) \\ 1015 Lausanne, Switzerland \\ ${ }^{2}$ Dept. of Neurology, Hadassah Hebrew University Hospital, Jerusalem, Israel \\ ${ }^{3}$ Department of Neurology, University Hospital, Geneva, Switzerland \\ (shahar.arzy@hcuge.ch,olaf.blanke@epfl.ch)
}

\begin{abstract}
Under normal conditions, human subjects experience the self within the limits of the physical body and the limits of the present time. This unified experience of the self in space and time has been challenged by philosophers and physicists. The spatial unity between self and body has also been challenged by a well defined group of experiences called "autoscopic phenomena" (AP), during which subjects have the impression of seeing a second own body in extrapersonal space. Yet, with respect to the three main forms of AP - autoscopic hallucination, heautoscopy, and out-of-body experience - previous studies have concentrated on describing the spatial unity between self and body while neglecting to analyze the temporal unity of self and body.

Here we describe several AP-cases with an altered experience of age or time for one's own body or self. In some AP-cases the second own body was seen as being younger or older than the subject's actual body. We show that the second own body is experienced as if "coming from another time" although the observing self is experienced in the present time. Other AP-subjects reported a feeling of timelessness of the observing self without any age difference between the subjects' actual and illusory body. We argue that these differences in age or time suggest that the temporal experience of one's own body and self is altered in these subjects.

Collectively, these data suggest that AP may be associated not only with abnormal sensations with respect to spatial unity, but also with respect to temporal unity. Moreover, we found that out-of-body experiences were associated with feelings of timelessness and no age differences between self and body and that autoscopic hallucinations and heautoscopy were associated with age differences between self and body but not with feelings of timelessness. We conjecture that out-of-body experiences are characterized by disembodiment not only in space but also in time. For autoscopic hallucinations and heautoscopy our findings suggest that the spatial displacement between self and body (without disembodiment) is accompanied by a temporal displacement of the body to a different time period than the present. We discuss these abnormal experiences of the bodily self in time and space and propose their potential functional and anatomical mechanisms.
\end{abstract}

Keywords: Autoscopic Phenomena - Out-of-Body Experience - Out-of-Time Experience - Temporo-Parietal Junction

${ }^{a}$ Corresponding author. 


\section{Introduction}

The self as an entity distinct from other human conspecifics may be described as an enduring and spatial entity (i.e. the feeling that one is the same person across time and space) to which certain mental events and actions are ascribed (i.e. the feeling of agency; being author of one's own thoughts and actions) and which is distinct from the environment [1]. Moreover, humans experience themselves to be located in a specific moment ("the present moment") and in a specific place ("the present place") [2]. Bermudez [3,4] suggested to define such a fundamental behaviour [5] in space and time as "non-conceptual", proposing that the behaving agent does not possess the concepts required to be aware of the contents of space and time. ${ }^{a}$

The many concepts of "self" have been influenced by theology, philosophy and psychology [6-9], but also by clinical observations from neurology and psychiatry $[1,10-13]$. Thus, several clinical conditions have been described during which the spatial or temporal self location is disturbed. With respect to spatial self location, experiences occurring in microgravity such as the inversion illusion during space missions or during the low gravity phase of parabolic flights (an spatial disorientation illusion in which pilots at least temporarily feel as though they are inverted relative to the earth; this illusion can be caused either by gravitoinertial forces or by visual factors; [14-16]) and the room tilt illusion (a transient tilt perception of the extrapersonal visual space on its side or upside down, with respect to a stable observer might be mentioned. Both experiences have also been reported in neurological and otological patients [17-19]). When referring to disturbances of temporal self location, authors have mentioned conditions such as delusional misidentification syndromes (DMS), which include among other reduplifications the reduplification of oneself in time [20,21]. Another clinical condition during which temporal self location is disturbed are spontaneous confabulations (i.e. acting on the basis of previous habits rather than currently relevant memories). These patients have been reported to produce confabulations about themselves that are composed of elements of past true events, present actions and future imaginations [22,23]. Especially relevant to our present investigation about spatial and temporal self processing is the group of clinical phenomena of autoscopic phenomena (AP). AP are generally defined as illusory visual experiences during which the subject has the impression of seeing a second own body in extraper-

${ }^{a}$ Such subject-effected mental states are found in non-linguistic behavior and subpersonal computational constructions (like the Chomskyan approach to syntax) [3]. 
sonal space associated with varying degrees of separation of the self from the body. $[10,13,24,25]$. Thus, it has been argued that AP challenge our notions about the experienced spatial unity of self and body, localization of the self, as well as agency $[8,26]$. Interestingly, in some of these cases it has been reported that the autoscopic body (i.e., one's reduplificated body that is seen during the AP) is experienced as having a different age than the observing subject. Other AP-subjects have also reported a feeling of "timelessness" or changes in the experience of time. Thus, AP seem to challenge common conceptions of our experience of self location not only in space as commonly thought and analyzed, but also in time. The present review analyzes how body and self during AP are experienced with respect to temporal characteristics.

\section{Autoscopic Phenomena - Illusions of Body and Self in Space and Time}

During most AP a fundamental component of the self is isolated, as the self is not experienced as residing within the limits of one's body. Therefore it has been argued that AP present a valuable advantage to the study of the self [13,27-29]. Nevertheless, during the last century studies of AP are still rare in the neurological and scientific literature [10,13,30-35].

Three distinct forms of autoscopic phenomena have been defined (Fig. 1): (1) Autoscopic hallucination (AH): the experience of seeing a "double" of oneself in extrapersonal space viewed from the own physical body, i.e. in an AH the subject feels his "self" or center of awareness within the physical body $[10,13,34]$. (2) Out-of-body experience (OBE): the experience or feeling that the center of awareness is located outside of the physical body. The subjects experience seeing their body and the world from an elevated extrapersonal location that differs from their habitual position. Their perceptions are thus organized in such a way as to be consistent with this elevated visuo-spatial perspective $[13,32,33]$. (3) Heautoscopy (HAS): an intermediate form between AH and OBE. During HAS the subject also sees his double in extrapersonal space, but it may be difficult for the subject to decide whether he is disembodied or not or whether the self is localized in the physical or the double's body. In addition, subjects may experience the world from two simultaneous or alternating visuo-spatial perspectives: the habitual physical visuo-spatial perspective and an additional extracorporal perspective $[13,35]$. Despite of the association of AP with a wide range of neurological diseases such as epilepsy, migraine, neoplasm, infarction, and infection [33,34], they have also been reported in the general population, in 


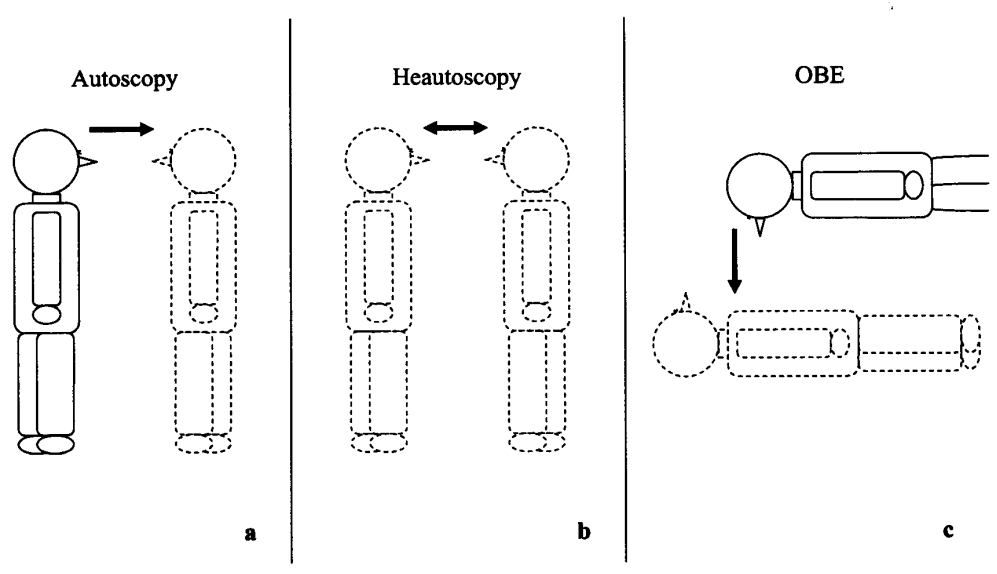

Figure 1. Phenomenology of Autoscopic Phenomena (AP). a) Autoscopic hallucination $(A H)$ : experience of seeing one's body in extracoporeal space (as a double) without disembodiment (experiencing the self as localized outside one's physical body boundaries). The double (right figure) is seen from the habitual egocentric visuo-spatial perspective (left figure). b) Heautoscopy (HAS): intermediate form between autoscopic hallucination and OBE; the subject experiences to see his body and the world in an alternating (or simultaneous) fashion from an extracorporeal and his bodily visuo-spatial perspective; often it is difficult for the subject to decide whether the self is localized in the double or in one's own body. c) Out-of-Body Experience (OBE): During an OBE the subject appears to "see" himself (bottom figure) and the world from a location above his physical body (extracorporeal location and visuo-spatial perspective; top figure). The self is localized outside one's physical body (disembodiment). The directions of the subject's visuo-spatial perspective during the AP is indicated by the arrows. Solid line represents the subject's point of view, dash line represents the "double".

approximately $10 \%$, where they occur only once or twice in a lifetime [27].

The above classification refers to AP by systematically describing the experienced position of one's body and self in spatial terms. Yet, one could not only analyze where the subject experiences the double (or autoscopic body) to be localized (i.e. in a different location in extrapersonal space with respect to the experiencing subject), but also when in time the subject experiences the double to be localized (i.e. is the double experienced as being younger or older than the subject; is the double localized in the present or not). In fact, there have been reports that the autoscopic body looks older or younger than the actual body of the subject during the AP and subjects have described these doubles to "come" from the past (younger double) or from the future (older double). Other subjects have not reported age-differences between autoscopic and physical body, but rather feelings 
of timelessness during the AP. As age-differences between autoscopic and physical body and feelings of timelessness in subjects with AP have not been systematically analyzed we decided to carry out such an analysis in the present study.

\section{Neuro-Phenomenology}

This chapter describes 20 cases of APs from the literature with abnormalities in the experience of time with respect to the patient's body and self. We quote and summarize the description of each subject and classify the experience with regard to spatial and temporal body and self location. Our analysis includes AP-cases from neurology and psychiatry, as well as healthy subjects.

\subsection{Sivadon ([36], observation no. 1; HAS, AH)}

A 50 year-old patient with influenza. In his first autoscopic experience he reports:

He became "two men: one who is walking and another who is lying on his bed and watches the other man". He knew himself perfectly and was not surprised. Some days afterwards he had another experience: "I saw in front of me a young man, nevertheless without strength, trying to get dressed, putting on his clothes with uncoordinated movements. And slowly I recognized myself in this silhouette, I recognized my hair and my face". ${ }^{b}$

In the second event this patient saw a young man in front of him. He did not recognize this young man immediately as he himself. He noticed the "painful" behaviour of his double, and characterized it as "half-sleeping". We classified this experience as AH since the autoscopic body appears in front of the subject, with no depersonalization [10], and no disembodiment or floating as in OBE. The first experience of the patient was classified as heautoscopy, since he had experienced himself simultaneously as "two men".

\subsection{Lhermitte ([37]; AH)}

A middle-aged man recovering from a severe myocardial infarct. Several days after the infarct the patient revealed a dream which 
he saw himself walking effortlessly. Suddenly he found himself in the presence of a person who turned his back on him, but he immediately recognized him, since this person was he himself; he himself but old, broken, bent like the elders, with worn-out clothes and an uncertain gait. "I said to myself, counting my disease, "like you here become old and handicap on the doorstep to the grave you are going to finish miserably".

The patient emphasizes the old age of his double, which he interprets as a clue to his destiny, caused by the disease. It is not clear if this experience occurred during dreaming, as a hypnagogic or hypopompic hallucination or during wakefulness. However, the description is of $\mathrm{AH}$ as the patient sees his double from the original body's point of view, with no disembodiment or depersonalization. Despite of the age difference and the back-view, the patient immediately recognizes the double as himself.

3.3 Hécaen and Ajuriaguerra ([31], observation no. 78; AH)

A 45 years old man with post traumatic stress disorder, without known brain damage or physiopathology. He describes his autoscopic experience:

"I am sitting at a table, and I have beside me or in front of me, another self [moi-même], who sits down and actually speaks to me, this is my double, I have the impression to see him materializing before me, in general this double speaks to me to tell me that I have messed up my life, and he calls me "you", he sits in the chair in front of my desk [...] I had the impression of seeing myself in a mirror, he thought like I did, but criticized me heavily, I have the impression that this is somebody else who knows me well, it is not me in front of me, but physically it is the same $[. .$.$] he has the same voice like me, but as younger, it$ seems to me as if he is younger than me. At this moment I had the impression to be in a situation like if I was in an unreal play [...] In these moments I believed the reality of the double".

The double is explicitly described as being younger than the patient. The double is speaking to the subject, and his younger voice is the first clue for the patient concerning the age differences between the autoscopic and physical body. Despite the immediate recognition, internally the subject feels strange to the personality of the double. We classified this experience as AH, since the "double" is described as "separated" from the body and there is only a weak affinity between the physical and autoscopic body. Also 
there is no description of depersonalization or disembodiment. The patient refers to mirror reflections to describe his experience of the autoscopic body, as has also been employed by other patients with AH (i.e. [38-40]). The subject is sitting in his chair, and so is the double.

\subsection{Schmidt ([41];AH)}

A woman of 35 years old, epileptic. At the moment when she woke up from a seizure, the patient saw [...] in front of her somebody who looked exactly like herself "like she was completely young and charming" who ran away, laughing. She tried to catch her, but failed and fell down.

This short passage describes an appearance of a younger autoscopic body, who runs away from the physical body. The experience is of $\mathrm{AH}$ as the patient experiences neither depersonalization nor disembodiment and sees her double in front of her. The double is exactly like the patient but "completely young". The double is in standing position, running away from the patient. The patient is trying to run after her young double.

\subsection{Green ([42]; 11 OBE-cases)}

$37.3 \%$ of Green's healthy OBE-subjects reported a change in their experience of the passage of time. This change was mostly described as if time did not exist or as if time passed more slowly or faster than usual. These abnormal experiences of time might overlap to a certain extent. Below we give the eleven cases that Green [42] has described.

1. "While I was out of my body there was no time at all, but once I had regained myself I realized the experience had taken few seconds."

2. "I omitted to mention the actual time that this experience took. It could have been minutes or hours, there was no sensation of time."

3. "I had no idea of time."

4. "There was a sense of 'timelessness'."

5. "The sensation was of a 'frozen instant'."

6. "Time seems to stand still."

7. "Time ceases to exist."

8. "I did not notice the passage of time at all: I think it was either completely suspended or so slow as to be almost imperceptible." 
9. "I was climbing a hard new route when a big block that I was holding on to came off and I fell down 90' [...] on that occasion I felt that I was watching from below and time seemed to pass very slowly."

10 "I loose all sense of time completely and feel afterwards that it has lasted hours but actually it is only a few minutes."

11. "It all seemed to take long time but it could be one second or less, because things go with the speed of light."

Of the eleven subjects reported by Green, $63 \%(\mathrm{n}=7)$ mention a feeling of 'timelessness', $18 \%(\mathrm{n}=2)$ report an experience of slowing of time-passage, and $9 \%$ an experience of accelerated time $(n=1) .9 \%(n=1)$ combine the two experiences with slowing of time following timelessness. Also note that in case 9, the experience of slowing of time was closely associated with disembodiment ("watching from below"). Thus the disturbance of the spatial and temporal unity between body and self were associated. No age differences were reported between autoscopic and physical bodies.

\subsection{Moody ([43], case 1; OBE)}

Moody claims that "almost everyone [of his subjects] remarks upon the timelessness of this out-of-body state [...] time was not really an element of their experience as it is in physical life", as in the following report:

I lost control of my car on a curve and the car left the road and went into the air [...] at that point I kind of lost my sense of time and I lost my physical reality as far as my body is concerned - I lost touch with my body. My being or my self or my spirit, or whatever you would like to label it, I could sort of feel it rise out of me, out through my head. And it wasn't anything that hurt, it was just sort of like a lifting and being above me [...] it seemed then as though time were standing still. At the first and the last of the accident, everything moved so fast, but this one particular time, sort of in between, as my being was suspended above me and the car was going over the embankment, it seemed that it took the car a long time to get there, and in that time I really wasn't to be involved with the car or the accident or my own body...

This description includes two characteristic elements of OBEs, disembodiment and elevated visuo-spatial perspective, but not explicit mentioning of autoscopy. The feeling of timelessness, described in the beginning of the 
experience, becomes in the continuation a feeling of tremendous slowness of the passage of time or fastness of the march of events. Also note that the experience of timelessness closely associated with disembodiment. Paraphrasing the patient we could say that he lost touch with his body and time. No age differences were reported between autoscopic and physical body.

\subsection{Moody ([43], case 2; OBE)}

When I came out of my physical body it was like I did come out of my body and go into something else [...] I can't describe it. I was more fascinated with everything around me, seeing my own body there $[\ldots]$ and all this seemed to go so quickly. Time wasn't really an element - and yet it was. Things seem to go faster after you get out of your body.

The subject describes all three elements of an OBE, extracorporal visuospatial perspective, disembodiment, and autoscopy. With respect to time, we see again the combination of timelessness ("time wasn't really an element") with the fastening of the events' passage or slowing of time as here. Again the subject notes that spatial and temporal characteristics between self and body interact by stating that "things seem to go faster after you get out of your body". No age differences were reported between autoscopic and physical body.

\subsection{Devinsky et al. ([24], case 9; AH)}

A 32 years old man had simple and complex partial seizures followed by generalized tonoclonic seizures since the age of 8 years. After initial control of 8 years the seizures recurred at age 16 years. The first episode of autoscopy had occurred at this time. The patient described the episode, saying "suddenly, I saw myself about five feet in front of me. My double was mowing the lawn, which is what I should have been doing." He has subsequently experienced autoscopy 15 times. His double is always a transparent, full figure that is slightly smaller than life size. It often wears different clothing than the patient and doesn't share the patient thoughts or emotions. The double is engaged in an activity that the patient feels he should be doing, and he says, "that guy is my guilty conscience". 
Unlike most of Devinsky et al.'s patients, who mentioned seeing their double in the same clothing they wear at the event, here the clothing is different. The difference in the clothing is a clue to the different age of the patient and his double. ${ }^{c}$ We suggest that the age of the autoscopic body might rather be slightly older than the physical body as the patient experiences the double carrying out activities that the patient feels he should be doing (in the future). The patient relates his guilty conscience as the cause of the double's appearance. The episode described here is classified as AH, as the patient describes seeing a double in front of him, while there is neither disembodiment, nor depersonalization.

\subsection{Blackmore ([44];OBE)}

OBEs may also be part of Near-Death-Experiences (NDEs) [43,44]. Next to OBEs, NDEs may also be characterized by a feeling of joy and peacefulness, the experience of passing through a tunnel, seeing of a light, a review of the person's life, and the return to life after the NDE. In addition, there might be an experience of timelessness. Blackmore describes 3 OBE-cases with such an experience of timelessness.

1. "I had an NDE type experience complete with the tunnel and light, out-of-body travels, expansion and contraction of size, timelessness, a mystical experience and the decision to return..." (p. 43)

Another NDE subjects report:

2. "It was like I lost time."

3. "I found myself in a space, in a period of time I would say, where all space and time was negated." ${ }^{d}$

With respect to timelessness Blackmore summarizes: "There can be a strange sense of timelessness in which everything happens very fast although time is not passing, or a sense that there is not even any order to time any more". Here, the first two cases describe their temporal experience as timeless. The third case describes experiencing a fast passage of the events. No age differences were reported between autoscopic and physical bodies.

${ }^{c}$ Double's clothing helped identifying OTE experience in other reports; see case 3.10 below; [32,34].

${ }^{d}$ It is not mentioned if these latter two had also OBEs, thus were not included in the statistics as different cases. 


\subsection{Blanke et al. ([13], patient 5; HAS)}

This patient, 43 year-old male, was known for familial hemiplegic migraine. Associated neurological symptoms were noticed since he was 19 years old. During his hospitalization he presented a complex partial seizure that was associated with AP:

The patient sits while a nurse is inserting a venous catheter to his arm. Suddenly he has the feeling that "it is all finished now. She will kill me". This was associated with a feeling of backward rotation of his body (accompanied with nausea and trembling). He had the feeling of seeing the world from two points of view: the original one and the rotated one. Towards the end of the rotation he suddenly noticed a presence of a person behind the nurse. Immediately he identified him as himself: "he looked like myself, but ten years younger. He was not dressed as I was. He hadn't the catheter, glasses and watch". He perceived the double as a real body in the extrapersonal space who comes to help him, and was deeply relived by his appearance. The double asked the original body "what am I supposed to do?" His response was: "help me get away from here; these people want to kill me!" then, a nurse and a doctor ran towards the patient. Here the double became active, and have been fighting with the doctor. Finally, the patient noticed a big black woman coming from behind, and physically inclines the chair backwards. He lost contact with his double and was put in bed by the medical staff.

The appearance of the double from the past is suggested by his looks, his clothing, his behavior and the absence of the catheter and watch of the patient. The double comes from the past, looks as in the past, but acts in the current situation. The patient's experience is HAS as he sees the world simultaneously from two points of view. The double is active and fighting. A feeling of trembling accompanies the experience, and a sense of relief. There is a dialogue between the double and the "I", or, at least, there is a mental communication which is perceived as a speech.

\section{Discussion}

We have analyzed 20 cases of APs in whom the temporal location of body or self was abnormal. $25 \%$ of cases $(\mathrm{n}=5)$ were classified as $\mathrm{AH}, 5 \%(\mathrm{n}=1)$ were classified as HAS and the majority $(70 \% ; \mathrm{n}=14)$ as OBE (Tab. 1). Our 
findings show that the unitary experience of self and body during AP is not only abnormal with respect to unity in space (self is localized in the body under normal conditions) but also (in the analyzed cases) with respect to unity in time (self is localized in the present under normal conditions). In addition, we found systematic differences in the temporal disunity between $\mathrm{AH} / \mathrm{HAS}$ as compared to OBEs. In the following we will discuss that AP not only challenge the unified experience of the self in time, but that they also allow to formulate more precise research hypotheses about the functional and neural mechanisms that participate in the construction of "self" across time.

All analyzed OBE-subjects had a feeling of timelessness or changes in the experience of time such as acceleration or slowing of time without any age differences between autoscopic and physical body. The disembodied subject (or self) during an OBE thus seems to experience seeing the own body from a "timeless" location or a location that is "out-of time". Accordingly, we have named this phenomenon "out-of-time experience" (OTE). Interestingly, this suggests that in phenomenological terms the spatial coordinates of the self (with respect to the body) and the temporal aspects of the self (with respect to the present) share important characteristics. Namely, the experience of being outside one's body is associated with the experience of being "outside" the present. This suggests that experience of the self in space and time might share functional and neural mechanisms, and temporal self mechanisms are influenced by spatial self mechanisms (or vice versa; see below).

With respect to AH/HAS the analyzed cases did not experience timelessness but experienced their physical body at the present moment. Yet, during $\mathrm{AH} / \mathrm{HAS}$ the autoscopic body was either experienced as older than the physical body ("as if coming from the future"; $33.3 \%$ ), or as younger ("as if coming from the past"; $66.6 \%$ ). Based on these data we suggest that the self in AH/HAS is experienced as being in the present and that the double (or autoscopic body) is experienced as being displaced into the future (older autoscopic body) or the past (younger autoscopic body). Again, this suggests that in phenomenological terms the spatial and temporal aspects of the self share important characteristics. Namely, whereas the self is experienced as being embodied and as being in the present, the (autoscopic) body is experienced as being in extrapersonal space and as coming from past or future.

In the following we try to account for the disturbed experience of temporal aspects of self and body in $\mathrm{AP}$ with respect to the cognitive and neural 


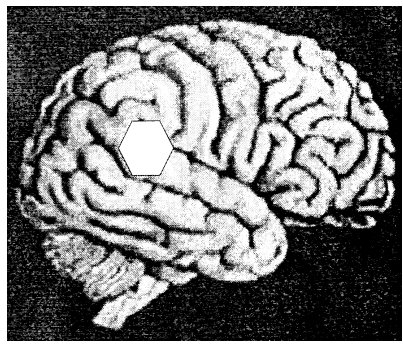

Figure 2. Temporo-parietal Junction. This brain region is supposed to be responsible to the integration of multisensory inputs and to self-processing, thus to creation of fundamental mental contents as agency, self-other distinction and self-location in time and space. Disturbance of the activity in this region may lead to AP, sometimes accompanied with OTE.

mechanism that have previously been described for AP. Yet, before proposing a model for disturbed experience of self and body in AP with respect to temporal aspects, we quickly resume what is known about it with respect to spatial characteristics. Studies suggest that in AP the integration of multisensory information of one's body (such as visual, tactile, proprioceptive, and vestibular information) has failed [10,13,29]. Such a failure might lead to the experience of seeing one's body in a position that does not coincide with its felt position as proposed for the effected body part in supernumerary phantom limbs $[11,45]$. It was further hypothesized that there are several brain areas, and especially the temporo-parietal junction (TPJ) $[13,26,29]$, that are responsible for the integration of the above mentioned multisensory information as well as self-processing data. When this area is disturbed either by pathology or by mental imagery this might facilitate the occurrence of AP $[25,29]$. Several neuropsychological and neuroimaging studies corroborate the important role of the TPJ (Fig. 2) and other cortical areas along the intraparietal sulcus in combining these tactile, proprioceptive, and visual information in a coordinated reference frame [46], in body perception [47-49], and in mental imagery with respect to one's own body $[25,50,51]$. The TPJ has also been involved in cognitive functions that are closely linked to self processing and AP: egocentric visuo-spatial perspective taking, agency and self-other distinction (the capacity by which one distinguishes between oneself and other particulars) [52]. Furthermore, the TPJ is the classical lesion site in patients with visuo-spatial neglect [12], a clinical condition, which has been shown to disturb the patient's egocentric spatial relationship with extrapersonal space and visuo-spatial 
perspective taking [53]. Neuroimaging studies in healthy observers have also revealed activation of the TPJ during egocentric visuo-spatial perspective changes [54,55]. Although many other cortical areas have been shown to play a role in self-processing, the reviewed neuroimaging data on body and self-processing as well as the clinical data on APs suggest that the TPJ is a key neural locus for self processing that is involved in multisensory body-related information processing as well as in processing of phenomenonological and cognitive aspects of the self. Thus, disturbance or lesion in this area might evoke AP $[13,25,29]$. Collectively, these studies have therefore shown a strong link of the TPJ for processing with respect to spatial self location. Yet, the TPJ has also been shown to play a central role also in time-processing [56-58]. In the following we will briefly review what is known about the TPJ with respect to temporal processing. We will then try to apply these findings to processing with respect to temporal self location.

The parietal part of the TPJ (the inferior parietal lobule: IPL) has been shown to be involved in a number of different time estimation tasks. Thus, lesions in this area and the prefrontal cortex have been shown to be critical for time discrimination and estimation deficits of several seconds $[59,60]$. The IPL was also found to be activated in sensorimotor synchronization tasks (of several seconds) [61,62], in time estimation tasks (of several seconds) [63-65] and in temporal discrimination (of milliseconds) [66-70], rhythm discrimination [71,72] and time counting (of hundreds milliseconds) [73]. Rubia and Smith [58] linked the involvement of IPL in time management to its role in attentional processing. However, as timeprocessing is an integral part of self-processing [56], we here speculate that the IPL (and TPJ) is one of the modules recruited for the integration of temporal self-processing. Thus, the TPJ is involved in immediate time management, i.e. seconds and hundreds of milliseconds, and especially in time-estimation and time-discrimination tasks and not (or less) in other time-processing aspects which are not connected to self-processing (like motor timing, pure time synchronisation or long time estimation) [58-60].

Despite this involvement of the TPJ in time-processing, these short time judgement of periods cannot easily be linked to the abnormal timeprocessing observed during AP that were experienced as spanning longer time periods and timelessness. Yet, this link might be provided by other studies that have investigated longer time periods as in autobiographical memory. Thus, the TPJ has been found to be activated in memory retrieval studies that use either PET [74-76], fMRI [77] or EEG [78], as a part of an 
autobiographical memory network that is composed by different structures in the frontal and temporal cortex as well as the hippocampus [74,79]. The right TPJ has also been shown to be involved in autobiographical episodic memory retrieval [74,77]. Interestingly, using PET during memory retrieval, Maguire and Mummery [80] differentiated between self-relevant (personal) memories with a specific time-location (personal/time; autobiographical events), self-relevant memories without time-location (personal/non-time; autobiographical facts), non-self-relevant memories with time-location (nonpersonal/time; public events) and non-self-relevant memories without timelocation (non-personal/non-time; general knowledge). ${ }^{e}$ Different activations were found for the different types of memories. Most interesting with respect to the present considerations, the TPJ activation showed a differential response to personal memories (personal) but did not discriminate between autobiographical events and facts (time and non-time), i.e. the TPJ was activated during personal memories independent of whether there was a time locus or not. In contrast, the medial frontal cortex, the hippocampus, and the temporal pole showed enhanced activity for stimuli that were personally relevant and had a specific locus in time (personal/time). ${ }^{f}$

In addition to the implication of the TPJ in AP, temporal processes and autobiographical memory, there are other neurological conditions that might help understanding the temporal disunity in $\mathrm{AP},{ }^{g}$ such as spontaneous confabulations and delusional misidentification syndromes (DMS). Confabulations have been defined as false memories occurring in clear consciousness in association with an organically derived amnesia [81]. Spontaneous confabulations act on the basis of previous habits rather than currently relevant memories. Thus, past true events and imaginations about the future interfere with the experienced present ('now') [22,23]. For instance, a 58-year-old neurological patient was convinced that she had to feed her baby, who was over 30 years old at the time [23,82]. It was suggested that the anterior limbic system provides a reality monitoring mechanism which selects memories of current relevance by suppressing (inactivating) currently irrelevant memories. Lesion in this area might thus cause involvement of irrelevant earlier (past) or imagined later (future) memories during

${ }^{e}$ Personal/time vs. personal/non-time reminds the differentiation between episodic autobiographical memory (conscious recollection of a temporally and spatially specific events from one's personal past) and semantic autobiographical memory, which is time independent $[89,90]$.

${ }^{f}$ Maguire and Mummery [80] remark that the preference of the TPJ to personal memories irrespective of temporal context has not been explored previously, but clearly requires further investigation.

${ }^{g}$ For a psychoanalytical explanation of AP in space and time see Rank [91]. 
the current processing of events [22,23]. DMS are a group of delusional disorders that involve a belief that the identity of a person, object or place has been changed or altered. Briefly, DMS include the syndrome of Capgras (the belief that (usually) a close relative or spouse has been replaced by an identical-looking impostor), the syndrome of Fregoli (the belief that various people that the believer has met are actually the same person in different disguises), the syndrome of intermetamorphosis (the belief that people in the environment switch identities with each other while maintaining the same appearance), the syndrome of subjective and inanimate doubles (AP or multiple duplications of oneself), and the syndrome of reduplicative paramnesias (the belief that a familiar event or place has been duplicated) $[20,21,83,84]$. Moreover, the different subtypes of DMS might co-appear $[20,21,85]$. Thus, although most authors think that reduplification of events concerns only the event and not the self $[20,84]$, the above reports and the co-appearance of subtypes in DMS suggest that DMS might combine AP with delusions of temporal-reduplication or event reduplification (i.e. agedifference between original body and autoscopic body). With respect to the anatomy of DMS, clinical and experimental evidence suggests that multifocal brain damage is necessary. Thus, right-posterior brain damage has been reported leading to deficits in visuo-spatial orientation and visual recognition. Also, the frequently associated bilateral frontal lobe pathology might be responsible for the patient's inability to correct the reduplicative phenomenon in the face of otherwise adequate mnemonic function, thus avoids correction by former knowledge and compensation mechanisms [21,83]. The above reviewed phenomena of AP, spontaneous confabulations, and DMS demonstrate that our immediate experience of being temporally located in the present moment, in a specific 'now', passing forward with time in an irreversible process depends on a variety of functions and brain areas. We suggest that the breakdown of the "now" in AP can be systematically examined leading to the description of some of the underlying functional and neural mechanisms of temporal self location.

\section{Conclusion}

In summary, our non-conceptual experience of self location inside our body and "inside" the present moment might be abnormal in various neurological conditions such as DMS, spontaneous confabulations and AP. The later are divided into $\mathrm{AH} / \mathrm{HAS}$, during which subjects experience seeing an autoscopic body from their habitual and embodied perspective, and OBEs, during which subjects appear to see the autoscopic body from a disembodied perspective. Our analysis showed that the abnormal spatial location 
of body and self during AP is sometimes accompanied by an abnormal temporal disunity of body and self.

Our analysis showed that OBE-subjects frequently report a sensation of "timelessness" as if seeing the passage of time from an outer pointof-view. We named this experience "Out-of-Time Experience" or OTE. We suggest that the spatial coordinates of the self (with respect to the body) and temporal aspects of the self (with respect to the present) share important characteristics because the experience of being outside of one's body (OBE) was found to be associated with the experience of being outside of the present moment (OTE). This suggests that the experience of the self in space and time might share functional mechanisms at the TPJ and other areas.

With respect to AH/HAS we did not encounter OTEs. Rather, the subjects reported being in the present moment, but experienced the autoscopic body as older or younger than the physical body. This suggests a differently disturbed self location in AH/HAS. Here, the double (or autoscopic body) is sometimes experienced as being displaced into the future (older autoscopic body) or the past (younger autoscopic body) showing again (as in OBE/OTE) that the spatial coordinates of the self and temporal aspects of the self share important functional mechanisms at the TPJ. Thus, the self is experienced as being embodied and in the present, whereas the autoscopic body is experienced as being in extrapersonal space and as coming from past or future.

The implication of the TPJ and especially the IPL (1) in time estimation and discrimination, (2) its involvement in autobiographical memory (independent of the autobiographical event's locus in time), (3) together with its central role in spatial self location and AP suggests that these abnormal experiences of the body and self in time might also be due to interference with the TPJ. The implication of many other brain areas and especially the prefrontal cortex in autobiographical memory, DMS, and spontaneous confabulations demonstrates that location of the self in time and space is not only processed at the TPJ, but in a largely distributed network. Whereas the implication of the different parts of the network certainly depend on the task or action the subject is performing, the reviewed clinical and neuroimaging data suggest that the TPJ plays a key role in spatial and temporal self location. We hope that the reviewed data will lead to further inquiries about how the brain generates our everyday experience of being placed in our body at the present moment. 


\section{References}

1. Kircher, T.T., Brammer, M., Bullmore, E., Simmons, A., Bartels, M., and David, A.S. (2002) The neural correlates of intentional and incidental self processing, Neuropsychologia 40, 683-692.

2. Stern, D. (2004) The Present Moment in Psychotherapy and Everyday Life, William Morrow \& Company, New York.

3. Bermudez, J.L. (1995) Nonconceptual content: from perceptual experience to subpersonal computational states, Mind and Language 10, 333-369.

4. Bermudez, J.L. (1998) The Paradox of Self-Consciousness, MIT, Cambridge.

5. Brewer, B. (1992) Self-location and agency, Mind 401, 17-34.

6. Neisser, U. (1988) The five kinds of self-knowledge, Phil. Psychol. 1, 35-59.

7. Gallagher, S. (2000) Philosophical conceptions of the self: implications for cognitive science, Trends Cogn. Sci. 4, 14-21.

8. Metzinger, T. (2003) Being No One. The Self-Model Theory of Subjectivity, Bradford Books, Cambridge.

9. Metzinger, T. (2005) The pre-scientific concept of a "soul". A neurophenomenological hypothesis about its origin, in M. Peschl (ed.), Auf der Suche nach dem Konzept/Substrat der Seele. Ein Versuch aus der Perspektive der Cognitive (Neuro-)Science, Königshausen und Neumann, Würzburg, in press.

10. Brugger, P., Regard, M., and Landis, T. (1997) Illusory reduplication of one's own body: phenomenology and classification of autoscopic phenomena, Cogn. Neuropsychiatry 2, 19-38.

11. Ramachandran, V.S. and Hirstein, W. (1998) The perception of phantom limbs, Brain 121, 1603-1630.

12. Halligan, P.W., Fink, G.R., Marshall, J.C., and Vallar, G. (2003) Spatial cognition. Evidence from visual neglect, Trends Cogn. Sci. 7, 125-133.

13. Blanke, O., Landis, T., Spinelli, L., and Seeck, M. (2004) Out-of-body experience and autoscopy of neurological origin, Brain 127, 243-258.

14. Lackner, J.R. (1992) Sense of body position in parabolic flight, Ann. N.Y. Acad. Sci. 656, 329-339.

15. Mittelstaedt, H. and Glassauer, S. (1993) Illusions of verticality in weightlessness, Clin. Investig. 71, 732-739.

16. Previc, F.H., Varner, D.C., and Gillingham, K.K. (1992) Visual scene effects on the somatogravic illusion, Aviat. Space. Environ. Med. 63, 1060-1064.

17. Solms, M., Kaplan-Solms, K., Saling, M., and Miller, P. (1988) Inverted vision after frontal lobe disease, Cortex 24, 499-509.

18. Tiliket, C., Ventre-Dominey, J., Vighetto, A., and Grochowicki, M. (1996) Room tilt illusion. A central otolith dysfunction, Arch. Neurol. 53, 1259-1264.

19. Malis, D.D. and Guyot, J.P. (2003) Room tilt illusion as a manifestation of peripheral vestibular disorders, Ann. Otol. Rhinol. Laryngol. 112, 600-605.

20. Weinstein, E.A. (1994) The classification of delusional misidentification syndromes, Psychopathology 27, 130-135.

21. Ellis, H.D., Luaute, J.P., and Retterstol, N. (1994) Delusional misidentification syndromes, Psychopathology 27, 117-120.

22. Schnider, A. (2000) Spontaneous confabulations, disorientation, and the processing of 'now', Neuropsychologia 38, 175-185. 
23. Schnider, A. (2001) Spontaneous confabulation, reality monitoring, and the limbic system - a review, Brain Res. Rev. 36, 150-160.

24. Devinsky, O., Feldmann, E., Burrowes, K., and Bromeld, E. (1989) Autoscopic phenomena with seizures, Arch. Neuro. 46, 1080-1088.

25. Blanke, O. (2004) Out of body experiences and their neural basis, BMJ $\mathbf{3 2 9}$, $1414-1415$.

26. Blanke, O., Mohr, C., Michel, C.M., Pascual-Leone, A., Brugger, P., Seeck, M., Landis, T., and Thut, G. (2005) Linking out-of-body experience and self processing to mental own-body imagery at the temporoparietal junction, $J$. Neurosci. 25, 550-557.

27. Blackmore, S.J. (1982) Beyond the Body. An Investigation of Out-of-Body Experiences, Heinemann, London.

28. Irwin, H.J. (1985) Flight of Mind. A Psychological Study of the Out-of-Body Experience, Scarecrow Press, Metuchen (NJ).

29. Blanke, O. and Arzy, S. (2005), Out-of body experiences due to disturbed self processing at the right temporo-parietal junction, Neuroscientist 11, 16-24.

30. Menninger-Lerchenthal, E. (1935) Das Truggebilde der eigenen Gestalt, Karger, Berlin.

31. Hécaen, H. and Ajuriaguerra, J. (1952) L'heautoscopie, in H. Hécaen and J. Ajuriaguerra (eds.), Meconnaissances et Hallucinations Corporelles, Masson, Paris, pp. 310-343.

32. Lukianowicz, N. (1958) Autoscopic phenomena, Arch. Neurol. 80, 199-220.

33. Grüsser, O.-J. and Landis, T. (1991) The splitting of 'I' and 'me'. Heautoscopy and related phenomena, in O.-J. Grüsser and T. Landis (eds.), Visual Agnosias and Other Disturbances of Visual Perception and Cognition, MacMillan, Amsterdam, pp. 297-303.

34. Dening, T.R. and Berrios, G.E. (1994) Autoscopic phenomena, Br. J. Psychiatry 165, 808-817.

35. Brugger, P., Agosti, R., Regard, M., Wieser, H.G., and Landis, T. (1994) Heautoscopy, epilepsy, and suicide, J. Neurol. Neurosurg. Psychiatry 57, 838839.

36. Sivadon, P. (1937) Phénomènes autoscopiques au cours de la grippe, Annales Médicine Psychologie 2, 215-220.

37. Lhermitte, J. (1951) Les phénomènes heautoscopiques, les hallucinations speculaires, in J. Lhermitte (ed.), Les Hallucinations. Clinique et Physiopathologie, G. Doin, Paris, pp. 124-168.

38. Féré, C. (1891) Note sur les hallucinations autoscopiques ou spéculaires et sur les hallucinations altruistes, C. R. Séanc Sociale Biologie 3, 451-453.

39. Sollier, P.A. (1903), Les Phénomènes d'Autoscopie, Félix Alcan, Paris.

40. Brugger, P. (2002), Reactive mirrors. Perspective taking in autoscopic phenomena, Cogn. Neuropsychiatry 7, 179-194.

41. Schmidt, B. (1948), L'heautoscopie, Chaiers de Psychyatrie 2, 21-26.

42. Green, C.E. (1968) Out-of-Body Experiences, Hamish Hamilton, London.

43. Moody, R. (1975) Life After Life, Bantam, New York.

44. Blackmore, S. (1993) Dying to Live: Near-Death Experiences, Prometheus Books, Buffalo. 
45. Ramachandran, V.S. and Blakeslee, S. (1998) Phantoms in the Brain, William Morrow \& Company, New York.

46. Calvert, G.A., Campbell, R., and Brammer, M.J. (2000) Evidence from functional magnetic resonance imaging of crossmodal binding in the human heteromodal cortex, Curr. Biol. 10, 649-657.

47. Bonda, E., Petrides, M., Frey, S. and Evans, A. (1995) Neural correlates of mental transformations of the body-in-space, Proc. Natl. Acad. Sci. USA 92, 11180-11184.

48. Downing, P.E., Jiang, Y., Shuman, M., and Kanwisher, N. (2001) A cortical area selective for visual processing of the human body, Science 293, 2470-2473.

49. Astafiev, S.V., Stanley, C.M., Shulman, G.L., and Corbetta, M. (2004) Extrastriate body area in human occipital cortex responds to the performance of motor actions, Nat. Neurosci. 7, 542-548.

50. Zacks, J.M., Rypma, B., Gabrieli, J., Tversky, B., and Glover, G. (1999) Imagined transformations of bodies. An fMRI study, Neuropsychologia 37, 10291040 .

51. Zacks, J.M., Ollinger, J.M., Sheridan, M.A., and Tversky, B. (2002) A parametric study of mental spatial transformations of bodies, Neuroimage 16, 857872 .

52. Decety, J. and Sommerville, J.A. (2003) Shared representations between self and other: a social cognitive neuroscience view, Trends Cogn. Sci. 7, 527-533.

53. Farrell, M.J. and Robertson, I.H. (2000) The automatic updating of egocentric spatial relationships and its impairment due to right posterior cortical lesions, Neuropsychologia 38, 585-595.

54. Maguire, E.A., Burgess, N., Donnett, J.G., Frackowiak, R.S., Frith, C.D., and O'Keefe, J. (1998) Knowing where and getting there: a human navigation network, Science 280, 921-924.

55. Ruby, P. and Decety, J. (2001) Effect of subjective perspective taking during simulation of action: a PET investigation of agency, Nat. Neurosci. 4, 546-550.

56. Nobre, A.C. and O'Reilly, J., (2004) Time is of the essence, Trends Cogn. Sci. 8, 387-389.

57. Mauk, M.D. and Buonomano, D.V. (2004) The neural basis of temporal processing, Annu. Rev. Neurosci. 27, 307-340.

58. Rubia, K. and Smith, A. (2004) The neural correlates of cognitive time management: a review, Acta Neurobiol. Exp. 64, 329-340.

59. Harrington, D.L., Haaland, K.Y., and Knight, R.T. (1998) Cortical networks underlying mechanisms of time perception, J. Neurosci. 18, 1085-1095.

60. Kagerer, F.A., Wittman, M., Szelag, E., and von Steinbchel, N. (2002) Cortical involvement in temporal reproduction: evidence for differential roles of the hemispheres, Neuropsychologia 40, 357-366.

61. Lejeune, H., Maquet, P., Pouthas, P., Bonnet, M., Casini, L., Macar, F., Vidal, F., Ferrara, A., and Timsit-Berthier, M. (1997) Brain activation correlates of synchronization: a PET study, Neurosci. Lett. 235, 21-24. 
62. Rubia, K., Overmeyer, S., Taylor, E., Brammer, M., Williams, S., Simmons, A., Andrew, C., and Bullmore, E. (2000) Functional frontalisation with age: mapping neurodevelopmental trajectories with fMRI, Neurosci. Biobehav. Rev. 24, 13-19.

63. Macar, F., Lejeune, H., Bonnet, M., Ferrara, A., Pouthas, V., Vidal, F., and Maquet, P. (2002) Activation of the supplementary motor area and of attentional networks during temporal processing, Exp. Brain Res. 142, 475-485.

64. Lewis, P.A. and Miall, R.C. (2002) Brain activity during non-automatic motor production of discrete multi-second intervals, Neuroreport 13, 1731-1735.

65. Basso, G., Nichelli, P., Wharton, C.M., Peterson, M., and Grafman, J. (2003) Distributed neural systems for temporal production: a functional MRI study, Brain Res. Bull. 59, 405-411.

66. Maquet, P., et al. (1996) Brain activation induced by estimation of duration: a PET study, Neuroimage 3, 119-126.

67. Pedersen, C.B., Mirz, F., Ovesen, T., Ishizu, K., Johannsen, P., Madsen, S., and Gjedde, A. (2000) Cortical centres underlying auditory temporal processing in humans: a PET study, Audiology 39, 30-37.

68. Rao, S.M., Mayer, A.R., and Harrington, D.L. (2001) The evolution of brain activation during temporal processing, Nat. Neurosci. 4, 317-323.

69. Belin, P., et al. (2002) The neuroanatomical substrate of sound duration discrimination, Neuropsychologia 40, 1956-1964.

70. Nenadic, I., Gaser, C., Volz, H-P., Rammsayer, T., Hager, F., and Sauer, H. (2003) Processing of temporal information and the basal ganglia: new evidence from fMRI, Exp. Brain Res. 148, 238-246.

71. Schubotz, R.I., Friederici, A.D., and von Cramon, Y.D. (2000) Time perception and motor timing: a common cortical and subcortical basis revealed by fMRI, Neuroimage 11, 1-12.

72. Numminen, J., Schurmann, M., Hiltunen, J., Joensuu, R., Jousmaki, V., Koskinen, S.K., Salmelin, R., and Hari R. (2004) Cortical activation during a spatiotemporal tactile comparison task, Neuroimage 22, 815-821.

73. Ortuno, F., Ojeda, N., Arbizu, J., Lopez, P., Marti-Climent, J.M., Penuelas, I., and Cervera, S. (2002) Sustained attention in a counting task: normal performance and functional neuroanatomy, Neuroimage 17, 411-420.

74. Fink, G.R., Markowitsch, H.J., Reinkemeier, M., Bruckbauer, T., Kessler, J., and Heiss, W.D. (1996) Cerebral representation of one's own past: neural networks involved in autobiographical memory, J. Neurosci. 16, 4275-4282.

75. Cabeza, R., Mangels, J., Nyberg, L., Habib, R., Houle, S., McIntosh, A.R., and Tulving, E. (1997) Brain regions differentially involved in remembering what and when: a PET study, Neuron 19, 863-870.

76. Piolino, P., Giffard-Quillon, G., Desgranges, B., Chetelat, G., Baron, J.C., and Eustache, F. (2004) Re-experiencing old memories via hippocampus: a PET study of autobiographical memory, Neuroimage 22, 1371-1383.

77. Levine, B., Turner, G.R., Tisserand, D., Hevenor, S.J., Graham, S.J., and McIntosh, A.R. (2004) The functional neuroanatomy of episodic and semantic autobiographical remembering: a prospective functional MRI study, J. Cogn. Neurosci. 16, 1633-1646. 
78. Wilding, E.L. and Rugg, M.D. (1996) An event-related potential study of recognition memory with and without retrieval of source, Brain 119, 889-905.

79. Lee, A.C., Robbins, T.W., Graham, K.S., and Owen, A.M. (2001) "Pray or Prey?" dissociation of semantic memory retrieval from episodic memory processes using positron emission tomography and a novel homophone task, $\mathrm{Neu}$ roimage 16, 724-735.

80. Maguire, E.A. and Mummery, C.J. (1999) Differential modulation of a common memory retrieval network revealed by positron emission tomography, Hippocampus 9, 54-61.

81. Berlyne, N. (1972) Confabulation, Br. J. Psychiatry 120, 31-39.

82. Schnider, A., von Daniken, C., and Gutbrod, K. (1996) The mechanisms of spontaneous and provoked confabulations, Brain 119, 1365-1375.

83. Benson, D.F., Gardner, H., and Meadows, J.C. (1976) Reduplicative paramnesia, Neurology 26, 147-151.

84. Voros, V., Tenyi, T., Simon, M., and Trixler, M. (2003) 'Clonal pluralization of the self': a new form of delusional misidentification syndrome, Psychopathology 36, 46-48.

85. Sno, H.N. (1994) A continuum of misidentification symptoms, Psychopathology 27, 144-147.

86. Tsuruta, S. (1994) Age-delusion: age-misidentification of chronic schizophrenic patients, Seishin Shinkeigaku Zasshi 96, 755-773.

87. Rotenberg, M. (1983) Dialogue with Deviance: the Hassidic Ethic and the Theory of Social Contraction, University Press of America, Philadelphia.

88. Rotenberg, M. (1987) Re-Biographing and Deviance: Psychotherapeutic Narrativism and the Midrash, Prager Publications, New York.

89. Tulving, E. and Markowitsch, H.J. (1998) Episodic and declarative memory: Role of the hippocampus, Hippocampus 8, 198-204.

90. Levine, B. (2004) Autobiographical memory and the self in time: brain lesion effects, functional neuroanatomy, and lifespan development, Brain Cogn. 55, $54-68$.

91. Rank, O. (1925) Der Doppelganger: Eine psychoanalytische Studie, Internationaler Psychoanalytischer Verlag, Leipzig. 


\section{Appendix A: Therapeutic Considerations}

Tsuruta [86] noticed that schizophrenic patients who believe to be in a different age than their chronological one might get an advantage from the phenomenon, as "believing in their subjective age seems to allow them to reunify or rewrite their own past history and gain some hope for the future". The psychotherapeutic method of hermeneutic re-biography uses similar conditions. The method tries to repair the past by re-reading the patient's history from a different temporal point of view, and then to shape the future accordingly $[87,88]$. However, how is the therapeutic-migrating through rereading of past failure possible without changing facts or events? And how can one write a script of one's future realistically? Rotenberg suggests that "we must realize that we can understand the possibility of dialogue between one's past "I" and one's future "I" only in terms of the balance between the finite rational-material and the infinite mystic-spiritual conceptions of life that prevail in particular cultures" [88, p. 180]. The reviewed data suggest that the neurocognitive phenomena of AP facilitate such changes in temporal self location.

In AP one may see his double in the past or in the future, under positive or negative circumstances. Thus, case 10 of the current study faces his younger double, who helps him to get back his force and fight his unwilled position (past, positive). Case 3 hears from his younger double that the temporary reading of his life is a failure (past, negative). The dialogue with the past double may lead to a new reading of the self biography. Case 2 sees his imagined future double broken and ill (future, negative). The manifestation of such a future should lead the subject to change his way of life. On the other hand, Case 8's double is coming from the future, showing the subject a possible, recommended future (future, positive). Thus, AP with age-difference between the original body and the autoscopic body claim for open future and past and suggest alternative probable outcomes, thus assist re-biographing mental states. 
Table A.1. Phenomenological findings of Autoscopic Phenomena and time-experience $(\mathrm{AP}=$ Autoscopic Phenomena; HAS = HeAutoScopy; AH = Autoscopic Hallucination; $\mathrm{OBE}=$ Out-of-Body Experience; DP = Depersonalization; DE = Disembodiment; n.r. $=$ not reported)

\begin{tabular}{|c|c|c|c|c|c|c|c|}
\hline $\begin{array}{c}\text { Subj. } \\
\quad \#\end{array}$ & Ref. & $\mathrm{AP}$ & $\mathrm{DP}$ & $\mathrm{DE}$ & $\begin{array}{l}\text { Time of } \\
\text { Double }\end{array}$ & Action & Speech \\
\hline 1 & {$[36]$} & $\begin{array}{c}\mathrm{AH} \\
\mathrm{HAS}\end{array}$ & \pm & - & past & n.r. & - \\
\hline 2 & {$[37]$} & $\mathrm{AH}$ & - & - & future & walking & + \\
\hline 3 & {$[31]$} & $\mathrm{AH}$ & - & \pm & past & - & + \\
\hline 4 & {$[41]$} & $\mathrm{AH}$ & - & - & past & $\begin{array}{l}\text { running, } \\
\text { laughing }\end{array}$ & n.r \\
\hline 5 & $\begin{array}{c}{[42]} \\
(11 \text { subj's })\end{array}$ & $\mathrm{OBE}$ & + & + & timeless & - & - \\
\hline 6 & {$[43 ; \mathrm{C} 1]$} & OBE & + & + & timeless & - & - \\
\hline 7 & {$[43 ; \mathrm{C} 2]$} & $\mathrm{OBE}$ & + & + & timeless & - & - \\
\hline 8 & {$[24]$} & $\mathrm{AH}$ & - & - & $\begin{array}{l}\text { near } \\
\text { future }\end{array}$ & $\begin{array}{l}\text { moving } \\
\text { the lawn }\end{array}$ & - \\
\hline 9 & {$[44]$} & $\mathrm{OBE}$ & n.r. & n.r. & timeless & - & - \\
\hline 10 & {$[13]$} & HAS & + & - & past & fighting & + \\
\hline
\end{tabular}

\begin{tabular}{|ccccccc|}
\hline $\begin{array}{c}\text { Subject's } \\
\text { Position }\end{array}$ & $\begin{array}{c}\text { Double's } \\
\text { Position }\end{array}$ & Gender & Weak & Fear & Surprise & $\begin{array}{c}\text { Vestib. } \\
\text { Manifest. }\end{array}$ \\
\hline n.r.supine & standing & $\mathrm{m}$ & double & n.r. & - & \pm \\
standing & standing & $\mathrm{m}$ & + & n.r. & n.r. & n.r. \\
sitting & sitting & $\mathrm{m}$ & n.r. & n.r. & n.r. & n.r. \\
- & standing & $\mathrm{f}$ & n.r. & n.r. & n.r. & n.r. \\
n.r. & n.r & n.r. & n.r. & n.r. & n.r. & + \\
n.r. & n.r & n.r. & n.r. & n.r. & n.r. & + \\
n.r. & n.r & n.r. & n.r. & n.r. & n.r. & + \\
n.r. & standing & m & n.r. & n.r. & + & n.r. \\
n.r. & n.r & n.r. & n.r. & n.r. & n.r. & + \\
sitting & standing & m & + & + & + & + \\
\hline \hline
\end{tabular}

